\title{
Juvenile xanthogranuloma of the ear: A case report
}

\author{
M Amir Mrad MD, Kevin Chan BHSc, Tatiana KS Cypel MD, Ronald M Zuker MD FRCSC FACS FAAP
}

\begin{abstract}
MAMrad, KChan, TKS Cypel, RMZuker. Juvenile xanthogranuloma of the ear: A case report. Can J Plast Surg 2008;16(4):229-231.

Juvenile xanthogranuloma is a relatively uncommon, benign histiocytic proliferative disorder. A case of juvenile xanthogranuloma in a 13-monthold girl with an unusual clinical form is described. She presented with a yellow-red projecting nodule over the helical rim of her right ear. The lesion was histologically diagnosed as juvenile xanthogranuloma after excisional biopsy. Although primarily a dermatological curiosity, plastic surgeons should be familiar with this entity, and should consider it in the differential diagnosis of benign soft tissue tumours of the ear.
\end{abstract}

Key Words: Ear; Ear tumours; Juvenile xanthogranuloma; Skin lesions

\section{Un xanthogranulome juvénile de l'oreille : Un rapport de cas}

Le xanthogranulome juvénile est une histiocytose auto-involutive bénigne relativement rare. Un cas de xanthogranulome juvénile à la forme clinique inhabituelle chez une fillette de 13 mois est présenté. Elle avait un nodule saillant d'un jaune rougeâtre sur la bordure hélicoïdale de l'oreille droite. Après biopsie de l'excision, l'histologie a permis de diagnostiquer un xanthogranulome juvénile. Bien qu'il s'agisse principalement d'une curiosité dermatologique, les chirurgiens plasticiens devraient connaître cette entité et l'envisager au moment du diagnostic différentiel des tumeurs bénignes des tissus mous de l'oreille.

$J$

uvenile xanthogranuloma (JXG) is a well-recognized entity that was first described approximately a century ago by Adamson (1). It is the most common form of non-Langerhans cell histiocytosis (2). For the most part, JXG is a benign cutaneous fibrohistiocytic lesion that usually presents during infancy or early childhood. Classically, it presents as solitary or multiple yellowish papules or nodules. The most common sites of involvement are the head, neck and trunk (2). In recent years, however, it has become increasingly clear that there are numerous clinical forms of JXG beyond this classic description. In such cases, the diagnosis may be more difficult to make without knowledge of the different possible clinical variants. We describe a case of JXG with a rather unusual clinical presentation, and highlight the importance of considering this entity in the differential diagnosis of benign soft tissue tumours of the ear.

\section{CASE PRESENTATION}

A 13-month-old girl was referred to the Division of Plastic and Reconstructive Surgery, The Hospital for Sick Children, Toronto, Ontario, for a soft tissue mass over the helical rim of her right ear (Figures 1 and 2), which was first noticed six months earlier as an area of redness. The mass continued to grow and eventually became quite prominent with crust formation and occasional bleeding. The girl was otherwise healthy.

On physical examination, the right ear was remarkable for a yellow-red projecting nodule over the helical rim, measuring $1.5 \mathrm{~cm} \times 1.0 \mathrm{~cm}$. There was a keratinous cap over the surface of the nodule that felt rubbery on palpation. There was no ulceration of the overlying skin and it did not appear to be fixed. Given these clinical features, the mass was initially suspected to be either a hemangioma or a pyogenic granuloma. However, due to uncertainty, an excisional biopsy was performed (Figures 3, 4 and 5).

Histological evaluation revealed a dermis expanded by predominantly multinucleated giant cells (up to an estimated 20 nuclei). Some of these cells contained foamy cytoplasm and others contained ingested lymphocytes and neutrophils. The

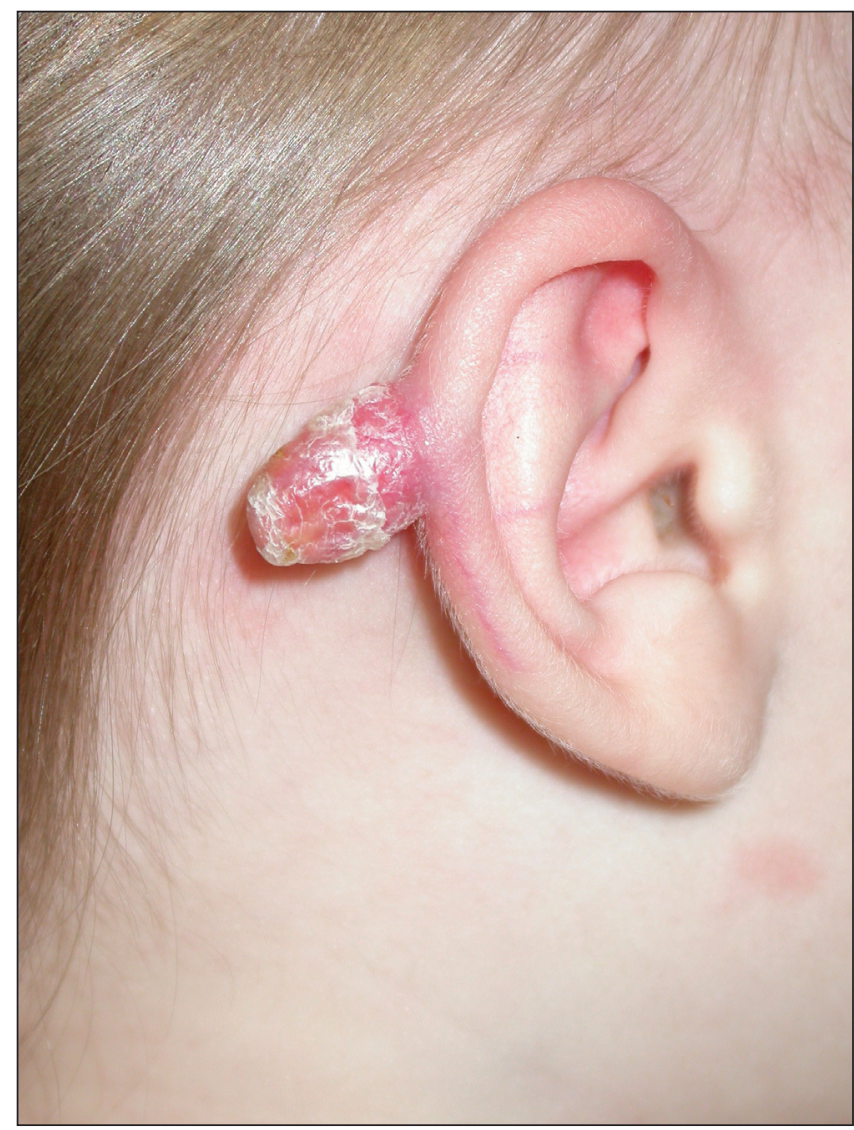

Figure 1) Side view of right ear xanthogranuloma

superficial portion of the lesion showed fibrosis and a xanthomatous infiltrate mixed with lymphocytes. An infiltrate of lymphocytes and plasma cells were also present throughout the lesion. Cells with cytological features of Langerhans histiocytes were not identified. Immunohistochemical analysis of the 


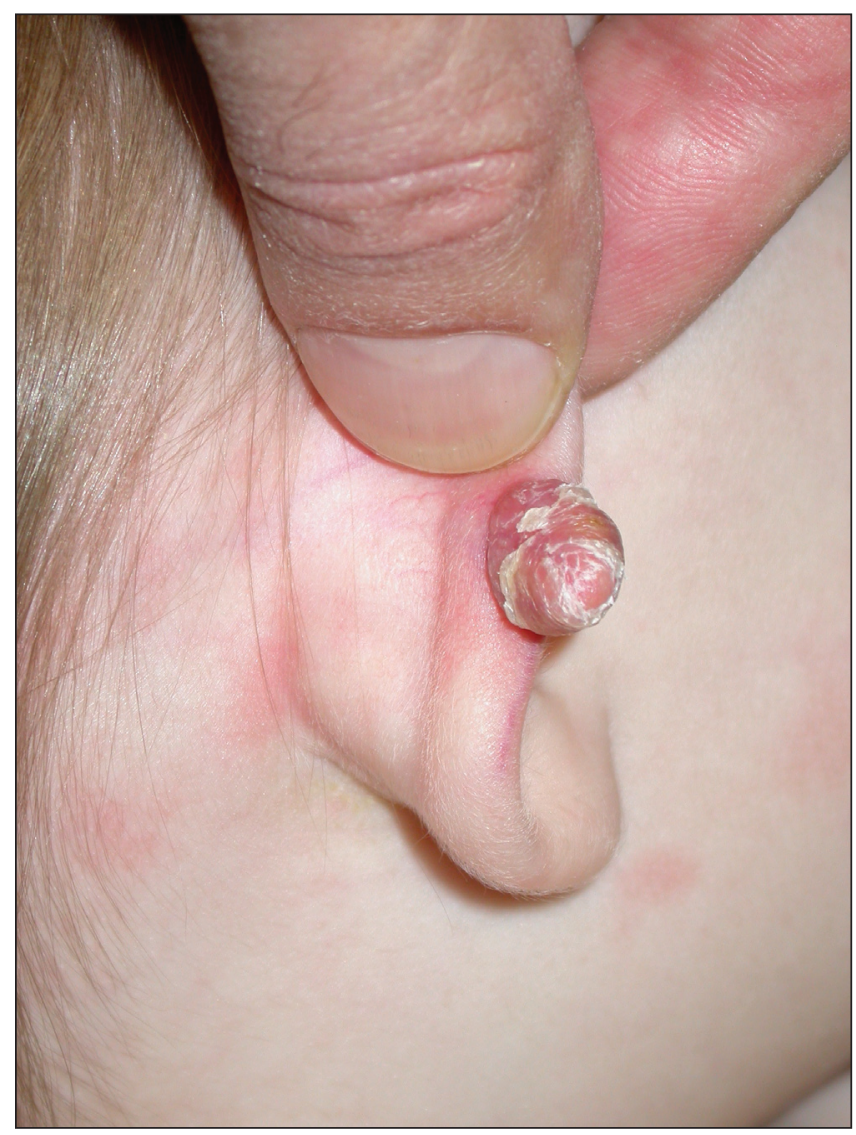

Figure 2) Side view of right ear xanthogranuloma with ear abducted

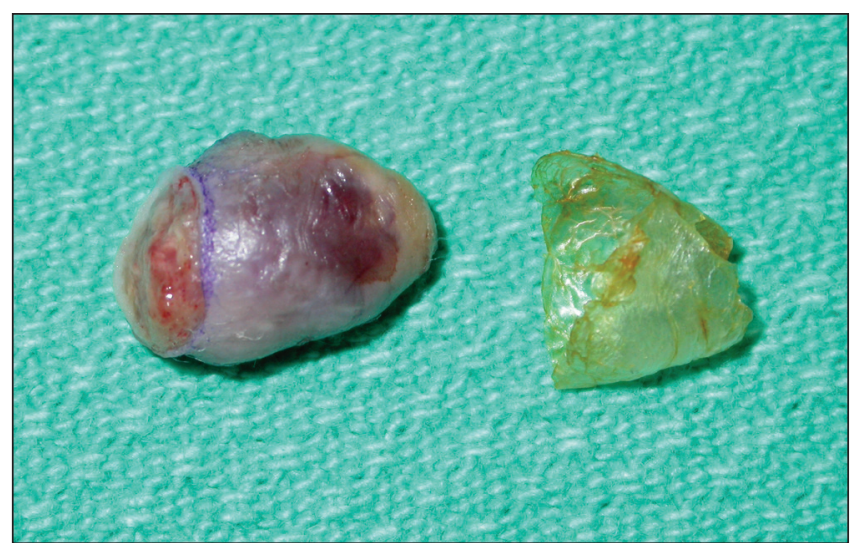

Figure 3) Gross pathology

lesional cells were positive for CD68 and factor XIIIa, but negative for S100, CD1a and Langerin. These combined clinical and histological findings were consistent with the diagnosis of JXG. Wound healing was uneventful (Figure 6).

\section{DISCUSSION}

JXG is a non-Langerhans cell histiocytosis that predominantly affects infants and children (2). Its usual presentation is characterized by solitary or multiple yellowish papules or nodules on the head, neck and trunk. The clinical course tends to be benign, and lesions spontaneously regress over a period of months to years (2). JXG may resolve completely or leave behind an area of residual hyperpigmentation, atrophy or anetoderma (2).

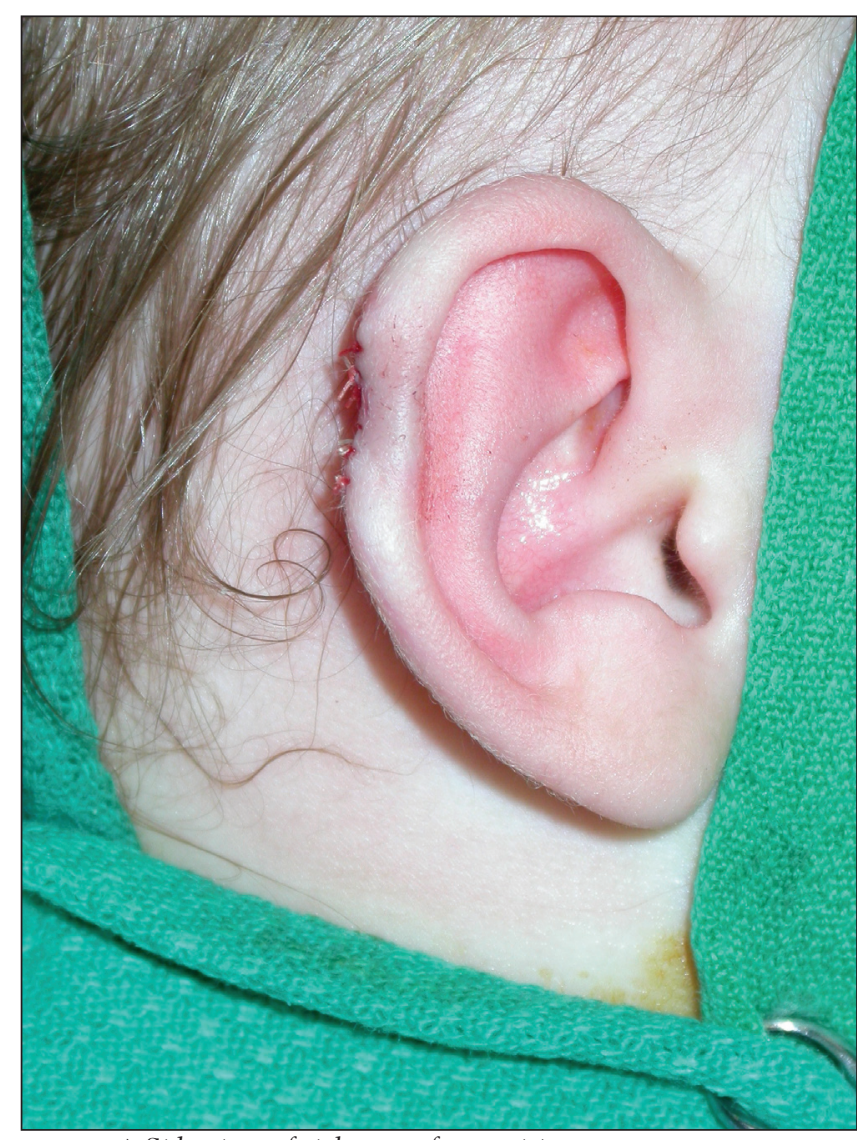

Figure 4) Side view of right ear after excision

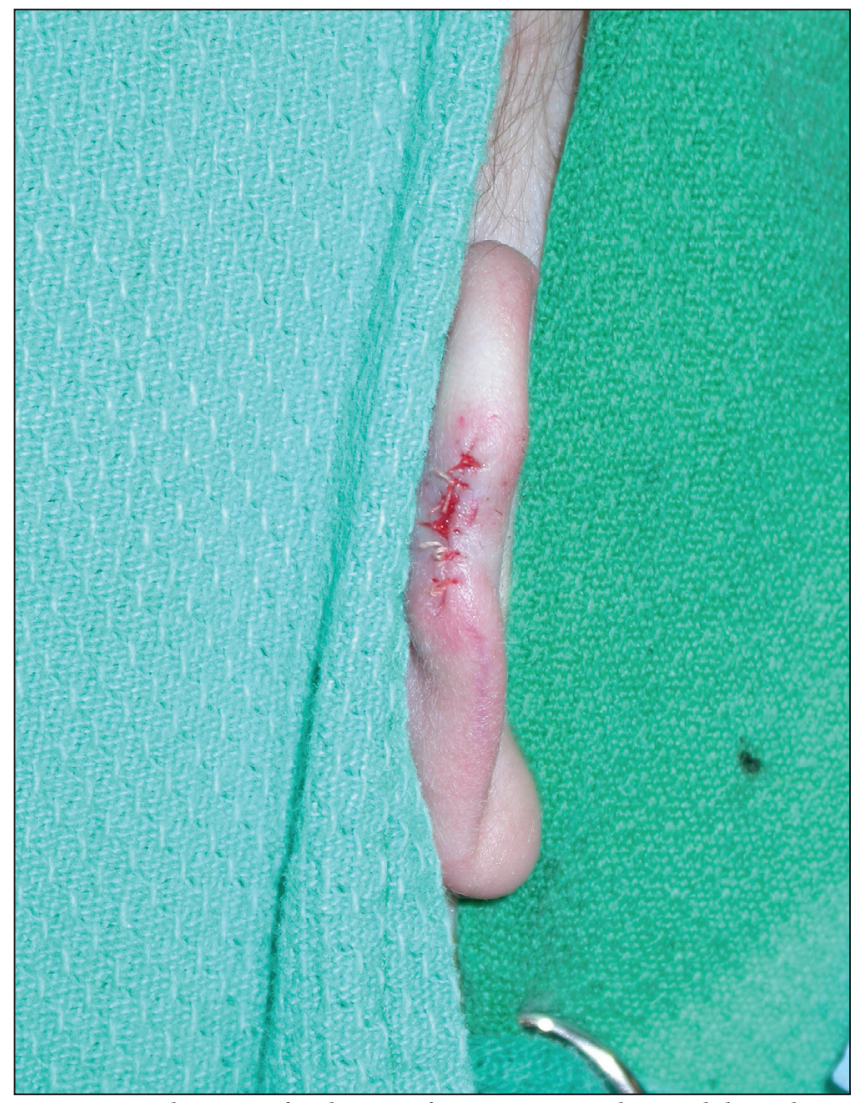

Figure 5) Side view of right ear after excision with ear abducted 
Histologically, JXG contains a dense dermal infiltrate of foamy histiocytes (2). Other cellular infiltrates include giant cells, Touton cells, lymphocytes, neutrophils and eosinophils (2). The presence of Touton cells are typical of JXG, but are not specific and may be absent $(2,3)$. Fibrosis may also be observed, especially in older regressing lesions (2). Immunohistochemical findings are important and proliferating histiocytes are usually negative for S-100 and CD1a and positive for HAM56 and factor XIIIa $(2,4)$.

These JXG features have been well characterized for several decades. However, what has made it both intriguing and peculiar is the increasing number of unusual cutaneous and systemic variants that are being reported in the literature. In fact, JXG can vary widely in terms of shape, size, location and distribution (2). As previously noted, the most common areas of involvement are the head, neck and trunk, but JXG can affect almost any site of the body, including the penis, eyelid, lips, palms, soles, fingers and intraorally (2,4-6). Intramuscular and subcutaneous JXG lesions have also been reported (4). Extracutaneous sites of involvement are possible as well, including the eye, central nervous system, lung, liver and spleen (4).

Cutaneous JXG can exhibit atypical variants, too. A giant form consists of unusually large nodular lesions, usually greater than $2 \mathrm{~cm}$ in diameter (4). The mixed form refers to the simultaneous occurrence of micro- and macronodules (4). A flat, plaque-like lesion has also been described (7). The paired variant demonstrates a remarkable presentation characterized by coupled lesions (7). Other uncommon types include a clustered form and a generalized lichenoid JXG (4). More recently, a cutaneous horn-like form has been reported (8).

Our patient presented with a rather uncharacteristic form of JXG and further confirms the wide spectrum of possible phenotypes. JXG can be readily recognized when it presents with the usual yellow cutaneous nodule, but it may not be suspected in atypical variants. Awareness of the different clinical forms is important and should facilitate diagnosis. Based on the present case, we recommend that all benign soft tissue tumours of the ear should include JXG as part of the differential diagnosis. Correct diagnosis is crucial and confers advantages by avoiding unnecessary invasive procedures and treatments.

ACKNOWLEDGEMENT: Dr Sandra Viero, staff pathologist at the Hospital for Sick Children.

CONFLICT OF INTEREST: No conflicts of interest to report.

ETHICS: The patient's family gave consent for the present case report.

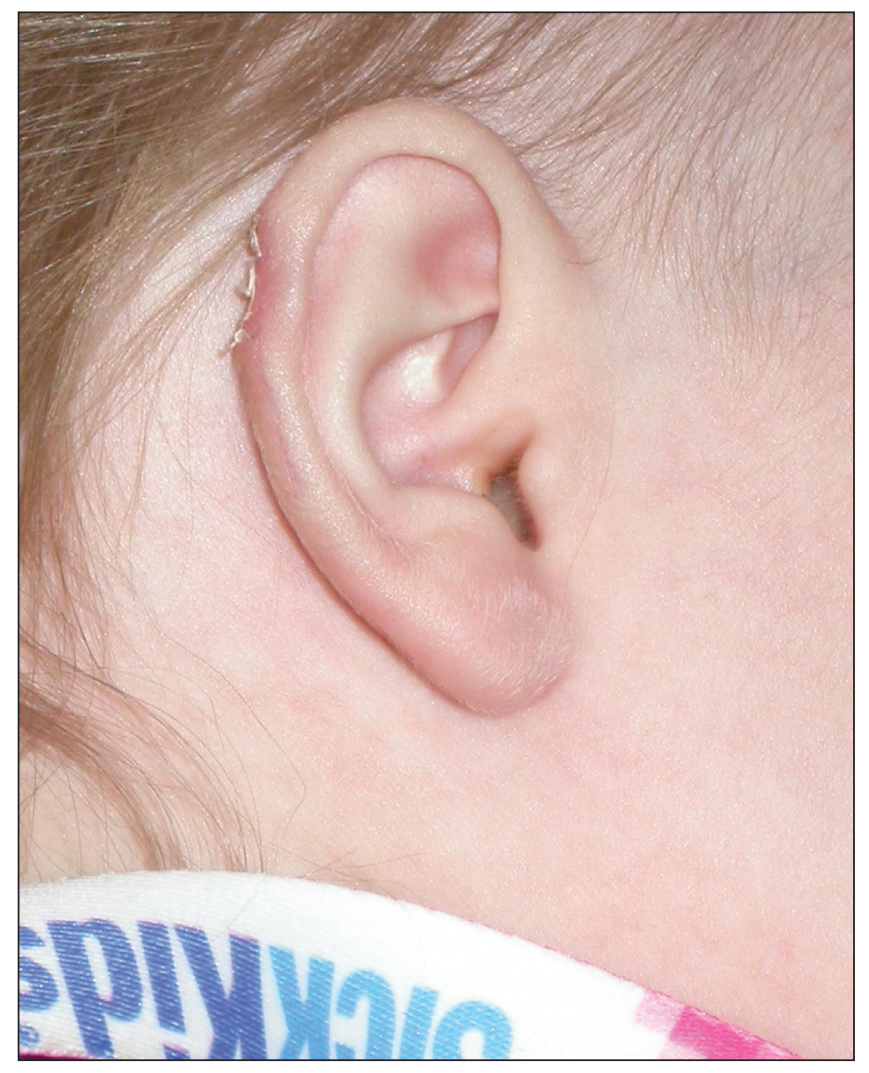

Figure 6) Result three weeks after excision (side view)

NOTE: Presented at the Canadian Society of Plastic Surgery annual meeting, St John's, 2008.

\section{REFERENCES}

1. Adamson NF. Congenital xanthoma multiplex in a child. Br J Dermatol 1905;17:222-3.

2. Hernandez-Martin A, Baselga E, Drolet BA, Esterly NB. Juvenile xanthogranuloma. J Am Acad Dermatol 1997;36:355-67.

3. Iwuagwu FC, Rigby HS, Payne F, Reid CD. Juvenile xanthogranuloma variant: A clinicopathological case report and review of the literature. Br J Plast Surg 1999;52:591-6.

4. Chang MW. Update on juvenile xanthogranuloma: Unusual cutaneous and systemic variants. Semin Cutan Med Surg 1999;18:195-205.

5. Hughes DB, Hanasono MH, Nolan WB. Juvenile xanthogranuloma of the finger. Pediatr Dermatol 2006;23:53-5.

6. Matsuzaki A, Yo S, Isayama T. Juvenile xanthogranuloma of the hand. J Hand Surg 1984;9-B:341-2.

7. Caputo R, Cambiaghi S, Brusasco A, Gelmetti C. Uncommon clinical presentations of juvenile xanthogranuloma. Dermatology 1998;197:45-7

8. Motegi S, Nagai Y, Amano H, Tamura A, Ishikawa O. An unusual presentation of juvenile xanthogranuloma. Pediatr Dermatol 2007;24:576-7. 